\title{
Comparison of two different antibiotic regimens for the prophylaxisis of cases with preterm premature rupture of membranes: a randomized clinical trial
}

\author{
Ilker Kahramanoglu' ${ }^{1}$, Merve Baktiroglu ${ }^{2}$, Taylan Senol ${ }^{3}$, Ozge Kahramanoglu² $^{2}$ Enis Ozkaya ${ }^{3}$, \\ Olcay Ilhan², Fatma Ferda Verit'², Seyda Baydogan², Oguz Yucel ${ }^{2}$ \\ ${ }^{1}$ Department of Obstetrics and Gynecology, Cerrahpasa Medical Faculty, Istanbul University \\ ${ }^{2}$ Department Of Obstetrics And Gynecology, Suleymaniye Women's Health Training And Research Hospital \\ ${ }^{2}$ Department OfObstetrics And Gynecology, Zeynep Kamil Women And Children's Health Training And Research Hospital
}

\begin{abstract}
Objectives: The aim of the study was to assess the effect of $1 \mathrm{~g}$ ampicillin prophylactic dosage whether it is as effective as the dosage of $2 \mathrm{~g}$ to prevent maternal and neonatal morbidity in a randomized manner.

Materials and methods: One hundred and fourty eight singleton pregnant women with preterm premature rupture of membranes between 21 and 33 weeks of gestation were followed-up during the study period in our institution. We compared the efficacy of two different different dosages of ampicillin. The study population was randomized into 2 groups. In the group 1, $1 \mathrm{~g}$ of intravenous ampicillin was given every 6 hours. In the group 2, $2 \mathrm{~g}$ of intravenous ampicillin was given every 6 hours.

Results: There was no significant difference between groups interms of fetal complications (RDS, icterus, mortality, sepsis, transient tachypnea of newborn and the pneumonia), rate of intensive care unit admission, fetal gender, fever, rate of clinical chorioamnionitis, high white blood cell count and the CRP, rate of cases $<30$ weeks $(p>0.05)$. There was a significant difference between the groups for the rate of previous preterm premature rupture of membranes history, steroid administration and the need for tocolysis $(p<0.05)$.

Conclusions: Although antibiotics seems to be innocent, several side effects have been introduced. It is reasonable to use the lowest dosages in shortest period in order to minimize these unwanted effects.
\end{abstract}

Key words: preterm, rupture, membrane, chorioamnionitis, ampicillin, premature

Ginekologia Polska 2016; 87, 10: 701-705

\section{INTRODUCTION}

Prelabor or premature rupture of membranes (PPROM) is defined as rupture of membranes before onset of labor [1]. One third of preterm deliveries are observed as a complication of PPROM. PPROM is associated with several complications for both neonate and the mother [1]. Most of these complications are seen in cases with PPROM before 34 weeks of gestation [2]. Latency period for the cases with PPROM under expectant management was reported to be 1.5-4.6 days [3-5]. Therefore majority of the cases deliver within 48 hours and some in 7 days following rupture of membranes [3-7]. Randomized trials have shown that neonatal complications can be reduced with prolongation of latency period [8, 9]. Evidence based data lead the American College of Obstetricians and Gynecologists (ACOG) to prepare a clinical management guideline which recommends using prophylactic antibiotics to prolong pregnancy, reduce maternal infectious morbidity and reduce infectious and gestational age dependent neonatal morbidity $[1,10]$. Several antibiotic regimens have been proposed for PPROM prophylaxis including Ampicillin $2 \mathrm{~g}$ intravenously every 6 hours for 48 hours or 7 days alone (ampicillin $2 \mathrm{~g}$ intravenously every 6 hours for 48 hours or 7 days alone [11]. Dosages and the duration of prophylaxis for these kind of pregnancy complcation is still a debade. 
In this study, we tried to assess the effect of $1 \mathrm{~g}$ ampicillin prophylactic dosage whether it is as effective as the dosage of $2 \mathrm{~g}$ to prevent maternal and neonatal morbidity.

\section{MATERIAL AND METHODS}

This prospective randomized comperative study was conducted in the Department of Obstetrics and Gynecology at the Suleymaniye Women Health Research and Training Hospital, Istanbul, Turkey from January 1, 2011 to May 1, 2013. The hospital is a tertiary referral center with about 5600 deliveries per year. One hundred and fourty eight singleton pregnant women with PPROM between 21 and 33 weeks of gestation were followed-up during the study period in our institution. We compared the efficacy of ampicillin by the different dosages. The study population was randomized into 2 groups. In the group $1(n=84), 1 \mathrm{~g}$ of intravenous ampicillin was given every 6 hours. In the group 2 ( $n=74), 2 \mathrm{~g}$ of intravenous ampicillin was given every 6 hours. Sample size was calculated according to the study by Charan J et al. with $95 \% \mathrm{Cl}$ and $80 \%$ power [12].

Diagnosis of PPROM was based on a history of leaking fluid and visualization of amniotic fluid in the vagina. If PPROM was not obvious after inspection, the diagnosis was confirmed by positive results from a nitrazine test and ultrasonographic evaluation that demonstrated olighydramnios. Exclusion criteria were cervial dilatation more than $4 \mathrm{~cm}$, PPROM for $>48$ hours before admission, major fetal anomaly, chorioamnionitis, severe preeclampsia, allergic reaction to penicillin or any condition that would require the pregnancy to be terminated including maternal co-morbidity. In total, 158 patients were considered eligible for the study (Fig. 1). We compared the efficacy of two different dosages of ampicillin. The study included 2 groups. In the group $1,1 \mathrm{~g}$ of intravenous ampicillin was given every 6 hours. In the group 2, $2 \mathrm{~g}$ of intravenous ampicillin was given every 6 hours. All antibiotics were administered until delivery or up to 7 days. The patients with 24 weeks of gestation or more were treated with antenatal corticosteroid due to prematurity. During the follow-up, vaginal culture was performed at admission. The heart rate was monitored twice a day. Ultrasound examination was performed and fetal presentation, fetal weight and amniotic fluid volume was examined daily. Biophysical scoring and Doppler velocimetry were also performed when needed. Labor induction was prohibited prior to 34 weeks. Randomization was performed by using computer program (Randomization. com). The Ethical Committee of the Bakirkoy Dr. Sadi Konuk Hospital reviewed and approved the trial protocol and all participants provided written informed consent.

Data on the characteristics of the patients including maternal age, parity were collected. Gestational age at admission, gestational age at delivery, latency period were recorded. Additionally, we measured amniotic fluid index, white blood cell (wbc) count, C-reactive protein (CRP) level, rates of clinical chorioamnionitis, neonatal sepsis, neonatal pneumonia and respiratory distress syndrome (RDS). Clinical chorioamnionitis was diagnosed based on maternal temperature $\geq 38^{\circ} \mathrm{C}$ and two or more of the following conditions: (1) uterine tenderness; (2) wbc count > $15000 / \mathrm{mm}^{3}$; (3) foul-smelling vaginal discharge; (4) maternal tachycardia

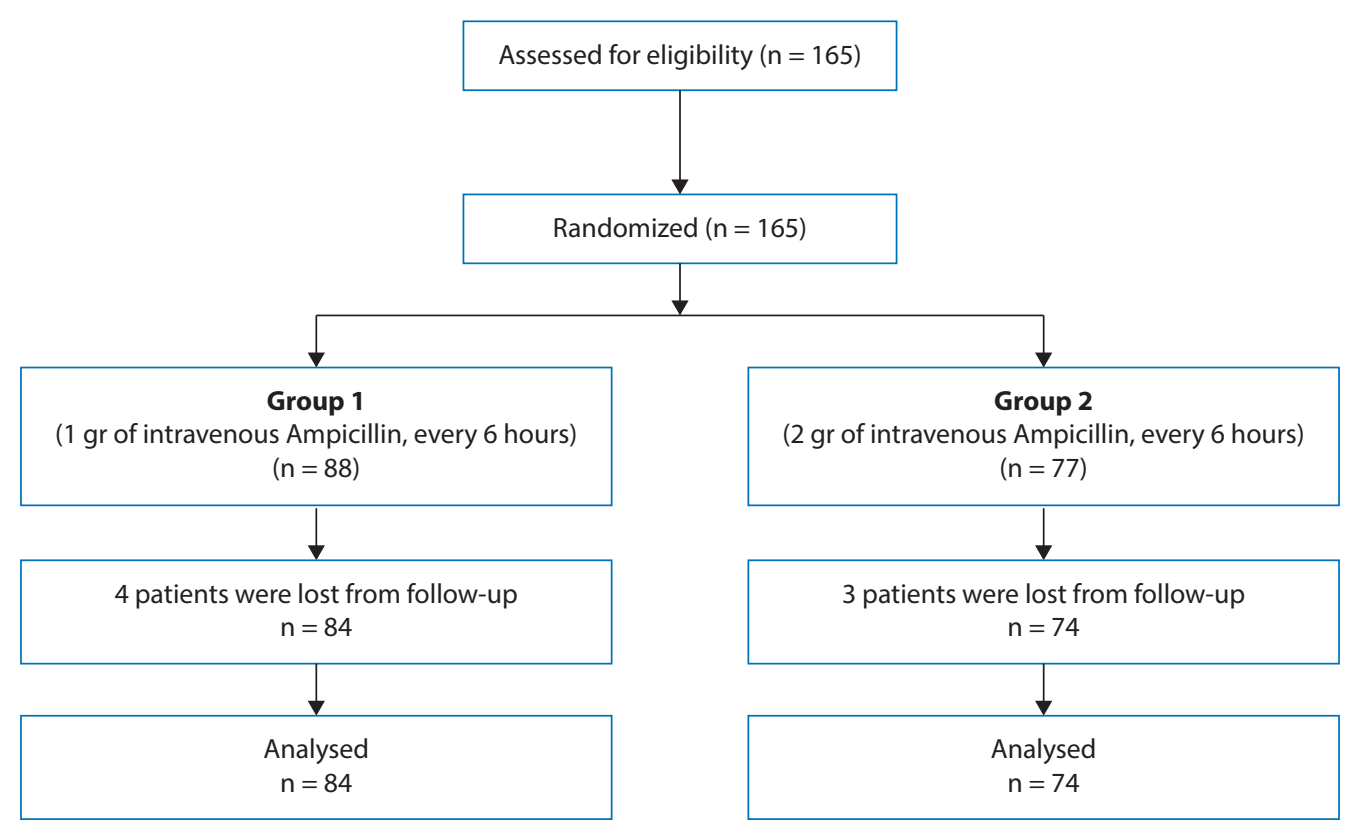

Figure 1. Flow of patients through the trial 
(<100 beats/min); and (5) fetal tachycardia (> 160 beats/min) as previously described (III). RDS was diagnosed in symptomatic infants who required ventilator support for at least 24 hours. Neonatal sepsis was diagnosed if there was a positive blood culture result obtained during the first 72 hours after birth. Pneumonia was diagnosed when an infant had compatible symptoms with diagnostic X-ray findings.

Statistical analysis was done using statistical software (SPSS 10.0 for Windows) and Student's t-test, Mann-Whitney $U$ test, McNemar's test and Friedman variance analysis were used, as appropriate. Signifance level was defined as 0.05. Data were expressed as mean \pm SD and percent (\%), where appropriate.

\section{RESULTS}

Some demographic and the clinical data for the whole study population is summarized in Table 1.

There was no significant difference between groups in terms of fetal complications (RDS, icterus, mortality, sepsis, transient tachypnea of newborn and the pneumonia), rate of intensive care unit admission, fetal gender, fever, high white blood cell count (23/84 vs. 24/74) and the CRP, rate of cases $<30$ weeks (23/84 vs. 22/74), the rate of previous PPROM history, steroid administration (39 vs. 55, respectively) and the need for tocolysis ( $10 \mathrm{vs.} 2$, respectively) ( $p>0.05$, Tab. 2). There was a significant difference between the low and high dosages groups for clinical choriamnionitis (18/84 vs. 8/74, $p<0.05)$.

\section{DISCUSSION}

In this study, we tried to compare two different dosages of same agent in cases with preterm premature rup- ture of membranes, our study revealed that two regimens result in similar outcomes except for the APGAR score at 1st minute, PPROM history, need for tocolyses and steroids. PPROM is seen in \%2.0-3.5 of pregnancies and $1 / 3$ of them result in preterm labor [13]. Prematurity is the most important cause of poor pregnancy outcome. Preterm deliveries account for 7 to $11 \%$ of the pregnancies [14, 15]. For that reason, management of PPROM is important for both prevention of preterm deliveries and the perinatal infections. Antibiotherapy provides interval for steroid administration. According to the literature, it is well known that steroid administration has some benefits of lower rates of respiratory distress syndrom, intraventricular hemorrhagia, necrotizing enterocolitis, need for neonatal respiratory support. Steroid administration is effective in up to 30 to $60 \%$ of the cases to prevent afforementioned complications $[16,17]$. In a systematic review comparing antibiotics to placebo in the management of PPROM, analyses of the data revealed significantly lower chorioamnionitis rates (RR 0.66, 95\% Cl 0.46-0.96), neonatal infections (RR 0.67, 95\% $\mathrm{Cl} 0.52-0.85$ ), need for surfactant administration (RR 0.83, $95 \% \mathrm{Cl} 0.72-0.96)$, need for neonatal respiratory support (RR $0.88,95 \% \mathrm{Cl} 0.81-0.96$ ) and probability of abnormal findings in cerebral ultrasound performed just before discharge (RR 0.81, 95\% Cl 0.68-0.98), in group under antibiotic prophylaxis [18]. Antibiotics seem to be beneficial in the management of PPROM $[9,18]$. On the other hand, Cochrane review showed that antibiotics could decrease short term neonatal morbidities but not perinatal mortality [19]. There is still a concern about the optimal effective antibiotic agent and the dosage, there is still need for further studies on

Table 1. Summary of some demographic and clinical characteristics of whole study population

\begin{tabular}{|c|c|c|c|c|c|}
\hline \multicolumn{6}{|c|}{ Descriptive Statistics } \\
\hline & $\mathbf{N}$ & Minimum & Maximum & Mean & Std. deviation \\
\hline Age (years) & 158 & 15 & 44 & 27.76 & 6.078 \\
\hline Gravidity & 158 & 1 & 12 & 2.43 & 1.899 \\
\hline Parity & 158 & 0 & 11 & 0.96 & 1.486 \\
\hline Gestational age at diagnosis (week) & 158 & 19.00 & 36.43 & 31.2793 & 4.03371 \\
\hline Gestational age at delivery (week) & 158 & 20.29 & 39.00 & 32.0371 & 3.81235 \\
\hline Interval & 158 & 0 & 53 & 5.30 & 8.265 \\
\hline Latency period (day) & 158 & 0 & 40 & 5.45 & 7.118 \\
\hline Initial AFI & 158 & 0 & 200 & 60.31 & 34.358 \\
\hline Apgar score at 1 minute & 158 & 0 & 9 & 6.20 & 1.780 \\
\hline Apgar score at 1 minute $<4$ & 158 & 1 & 2 & 1.93 & 0.253 \\
\hline Apgar score at 5 minutes & 158 & 0 & 10 & 7.78 & 1.744 \\
\hline Apgar score at 5 minutes $<7$ & 158 & 1 & 2 & 1.89 & 0.309 \\
\hline Duration of hospitalization of mother (day) & 158 & 1 & 42 & 7.55 & 7.152 \\
\hline Birth weight [g] & 158 & 280 & 3380 & 1910.62 & 647.898 \\
\hline
\end{tabular}


Table 2. Comparison summary of some demographic and clinical characteristics of two groups

\begin{tabular}{|c|c|c|c|c|c|c|}
\hline \multicolumn{6}{|c|}{ Group Statistics } & \\
\hline & Group & $\mathbf{N}$ & Mean & $\begin{array}{c}\text { Std. } \\
\text { deviation }\end{array}$ & $\begin{array}{l}\text { Std. error } \\
\text { Mean }\end{array}$ & \\
\hline \multirow{2}{*}{ Age (year) } & Low Dose & 84 & 27.5 & 5.8 & 0.6 & \\
\hline & High Dose & 74 & 28.1 & 6.3 & 0.7 & NS \\
\hline \multirow{2}{*}{ Gravidity } & Low Dose & 84 & 2.5 & 1.9 & 0.2 & \\
\hline & High Dose & 74 & 2.4 & 1.8 & 0.2 & NS \\
\hline \multirow{2}{*}{ Parity } & Low Dose & 84 & 0.9 & 1.3 & 0.1 & \\
\hline & High Dose & 74 & 1 & 1.5 & 0.2 & NS \\
\hline \multirow{2}{*}{ Gestational age at diagnosis (week) } & Low Dose & 84 & 31 & 4.4 & 0.5 & \\
\hline & High Dose & 74 & 31.6 & 3.5 & 0.4 & NS \\
\hline \multirow{2}{*}{ Gestational age at delivery (week) } & Low Dose & 84 & 31.8 & 4.2 & 0.5 & \\
\hline & High Dose & 74 & 32.3 & 3.4 & 0.4 & NS \\
\hline \multirow{2}{*}{ Interval } & Low Dose & 84 & 5.5 & 8.5 & 0.9 & \\
\hline & High Dose & 74 & 5 & 7.9 & 0.9 & NS \\
\hline \multirow{2}{*}{ Latency period (day) } & Low Dose & 84 & 5.6 & 8.1 & 0.8 & \\
\hline & High Dose & 74 & 5.2 & 5.9 & 0.6 & NS \\
\hline \multirow{2}{*}{ Initial AFI [mm] } & Low Dose & 84 & 63.06 & 34.1 & 3.7 & \\
\hline & High Dose & 74 & 57.22 & 34.6 & 4 & NS \\
\hline \multirow{2}{*}{ Apgar score at 1 minute } & Low Dose & 84 & 6.51 & 2 & 0.2 & \\
\hline & High Dose & 74 & 5.79 & 1.2 & 0.1 & $<0.05$ \\
\hline \multirow{2}{*}{ Apgar score at 1 minute $<4$} & Low Dose & 84 & 1.91 & 0.2 & 0.03 & \\
\hline & High Dose & 74 & 1.96 & 0.1 & 0.02 & NS \\
\hline \multirow{2}{*}{ Apgar score at 5 minute } & Low Dose & 84 & 7.9 & 2.1 & 0.3 & \\
\hline & High Dose & 74 & 7.5 & 0.8 & 0.1 & NS \\
\hline \multirow{2}{*}{ Apgar score at 5 minute $<7$} & Low Dose & 84 & 1.9 & 0.2 & 0.034 & \\
\hline & High Dose & 74 & 1.8 & 0.3 & 0.044 & NS \\
\hline \multirow{2}{*}{ Duration of hospitalization of mother (day) } & Low Dose & 84 & 7.4 & 7.3 & 0.8 & \\
\hline & High Dose & 74 & 7.6 & 6.9 & 0.8 & NS \\
\hline \multirow{2}{*}{ Birth weight [g] } & Low Dose & 84 & 1958.1 & 685.2 & 81.3 & \\
\hline & High Dose & 74 & 1856.1 & 603.2 & 76.6 & NS \\
\hline
\end{tabular}

this issue [20]. There have been studies on the antiobiotics including ampicillin, amoxicillin, azithromycin and erithromycin [9, 20, 21]. Comparison of ampicilin + erithromycin and ampicilin+azithromycin combinations revealed similar results. [21]. In an other study, eryhromycin was found to be associated with the higher risk for functional disorders and the cerebral palsy [8]. Amoxicillin-clavulanic acid combination resulted in higher rates of necrotizing enterocolitis in some studies $[8,22]$. Due to the effectiveness on group $B$ streptococcus, aerobic gram negative bacils and some anaerobic species, ampicillin is the most frequently used agent in PPROM prophylaxis [23]. According to the results of National Institute of Child Health and Human Development (NICHD) Maternal-Fetal Medicine Units (MFMU) Network trial on antibiotic therapy for reduction of infant morbidity after PPROM, ampicillin is recommended in $2 \mathrm{~g}$ doses for each
6 hours intervals [9]. In our study we compared two different dosages of ampicillin and found no difference in terms of maternal infections or neonatal poor outcome. The rate of chorioamnionitis was found to be higher in group under low dose protocol, however this difference did not reach statistical significance. It is well known that long duration and high doses of antibiotics may result in unfavorable outcome including allergic reactions, gastrointestinal disorders, cardiac arythmias and even mortality [24]. Major problem in using high doses of antibiotics for long time is higher risk for development of multiresistant bacterias [25, 26]. For example in England, frequently used agent erythromycin resulted in development of 35\% resistant bacterias [27, 28]. In addition, overuse of antibiotics may be associated with the anaphylactic reactions during pregnancy and the peripartum period (2,7 cases/100.000 deliveries) [29-31]. 
Anaphylaxis is a condition that threatenes both maternal and the fetal oxygenization. According to some studies, during the fetal and neonatal period, long term and high dose antibiotic exposure may result in allergic disease and abnormal intestinal flora development that may interfere with the immune system development [32-34]. Again according to the Cochrane review, beta lactam antibiotics with or without combination of macrolide were found to be associated with the higher rates of neonatal death compared to combinations without beta lactams (RR: 1.51; 95\% $\mathrm{Cl}=1.06-2.15$; NNTH: $143 ; 95 \% \mathrm{Cl}=63-1250$ ) [19].

In conclusion, antibiotic use seems to decrease neonatal morbidity in the management of PPROM. Although antibiotics seems to be innocent, several side effects have been reported. It is reasonable to use the lowest dosages in shortest period in order to minimize these unwanted effects while the half dosage ( $1 \mathrm{~g}$ of intravenous ampicillin, every 6 hours) is as effective as the present recommendation $(2 \mathrm{~g}$ ampicillin, every 6 hours).

\section{Conflict of interest}

The authors report no declaration of interest.

\section{REFERENCES}

1. ACOG Practice Bulletin No. 80. Premature rupture of membranes. Clinical management guidelines for obstetrician-gynecologists. Obstet Gynecol. 2007, 109, 1007-1019.

2. Pasquier JC, Picaud JC, Rabilloud M, [et al.]. Neonatal outcomes after elective delivery management of preterm premature rupture of the membranes before 34 weeks' gestation (DOMINOS study). Eur J Obstet Gynecol Reprod Biol. 2009, 143: 18-23.

3. Tsafrir Z, Margolis G, Cohen Y, [et al.]. Conservative management of preterm prematur rupture of membranes beyond 32 weeks' gestation: Is it wothwhile? J Obstet Gynaecol. 201, 35, 585-590.

4. Nelson LH, Anderson RL, O'Shea TM, [et al.]. Expectant management of preterm premature rupture of the membranes. Am J Obstet Gynecol. 1994, 171, 350-358.

5. Mercer BM, Crocker LG, Boe NM, [et al.]. Induction versus expectant management in premature rupture of the membranes with mature amniotic fluid at 32 to 36 weeks: a randomized trial. Am J Obstet Gynecol. 1993, 169, 775-782.

6. Bendix JM, Hegaard HK, Bergholt T, [et al.]. Expectant management of PPROM and major complicationsbefore planned delivery: A retrospective cohort study. J Obstet Gynaecol. 2015, 35, 570-577.

7. van der Heyden JL, van der Ham DP, van Kuijk S, [et al.]. Outcome of pregnancies with preterm prelabor rupture of membranes before 27 weeks' gestation: a retrospective cohort study. Eur J Obstet Gynecol Reprod Biol. 2013, 170: 125-130.

8. Kenyon SL, Taylor DJ, Tarnow-Mordi W. Broad-spectrum antibiotics for preterm, prelabour rupture of fetal membranes: the ORACLE I randomised trial. ORACLE Collaborative Group. Lancet. 2001, 357, 979-988.

9. Mercer BM, Miodovnik M, Thurnau GR, [et al.]. Antibiotic therapy for reduction of infant morbidity after preterm premature rupture of the membranes. A randomized controlled trial. National Institute of Child Health and Human Development Maternal-Fetal Medicine Units $\mathrm{Ne}-$ twork. JAMA. 1997, 278, 989-995.

10. ACOG practice bulletin: Premature rupture of membranes. Clinical management guidelines for obstetrician-gynecologists. Number 1,
June 1998. American College of Obstetricians and Gynecologists. Int J Gynaecol Obstet. 1998, 63, 75-84.

11. Yudin $\mathrm{MH}$, Van Schalkwyk J, Van Eyk N, [et al.]. Antibiotic therapy in preterm premature rupture of the membranes. J Obstet Gynaecol Can. 2009, 31, 863-867.

12. Charan J, Biswas T. How to calculate sample size for different study designs in medical research? Indian J Psychol Med. 2013, 35, 121-126.

13. Romero R, Athayde N, Maymon E, [et al.]. Premature rupture of the membranes. In: Reece A, Hobbins J, eds. Medicine of the fetus and mother. Philadelphia: Lippincott-Raven, 1999, 1581-625.

14. KhashoggiTY. Outcome of pregnancies with preterm prematüre rupture of membranes. Saudi Med J. 2004, 25, 1957-1961.

15. Lawn, JE, Kinney MV, Belizan JM, [et al.]. Born too soon: accelerating actions for prevention and care of 15 million newborns born too soon. Reprod. Health 2013, 10, Suppl 1: S6 doi: 10.1186/1742-4755-10-S1-S6.

16. Roberts $D$, Dalziel $S$. Antenatal corticosteroids for accelerating fetal lung maturation for women at risk of preterm birth. Cochrane Database Syst Rev. 2006; :CD004454.

17. Harding JE, Pang J, Knight DB, [et al.]. Do antenatal corticosteroids help in the setting of preterm rupture of membranes? Am J Obstet Gynecol. 2001, 184, 131-139.

18. Kenyon S, Boulvain M, Neilson JP. Antibiotics for preterm rupture of membranes. Cochrane Database Syst Rev. 2013, 12:CD001058.

19. Flenady V, Hawley G, Stock OM, [et al.]. Prophylactic antibiotics for inhibiting preterm labour with intact membranes. Cochrane Database Syst Rev 2013; 12:CD000246.

20. ACOG Committee Opinion No. 445: antibiotics for preterm labor. Obstet Gynecol. 2009, 114, 1159-1160.

21. Pierson RC, Gordon SS, Haas DM. A retrospective comparison of antibiotic regimens for preterm premature rupture of membranes. Obstet Gynecol. 2014, 124, 515.

22. Hoy CM. The role of infection in necrotising enterocolitis. Rev Med Microbiol. 2001, 12, 121-129.

23. Workowski KA, Berman S, Centers for Disease Control and Prevention (CDC). Sexually transmitted diseases treatment guidelines, 2010. MMWR Recomm Rep 2015, 64(RR-03): 1-137.

24. Rao GA, Mann JR, Shoaibi A,[et al.]. Azithromycin and levofloxacin use and increased risk of cardiac arrhythmia and death. Ann Fam Med. 2014, $12,121-127$.

25. Morales WJ, Dickey SS, Bornick P, [et al.]. Change in antibiotic resistance of group B streptococcus: Impact on intrapartum management. Am J Obstet Gynecol. 1999, 181, 310-314.

26. Heelan JS, Hasenbein ME, McAdam AJ. Resistance of group B streptococcus to selected antibiotics, including erythromycin and clindamycin. J Clin Microbiol. 2004, 42, 1263-1264.

27. Tan S, Holliman R, Russell AR. Hazards of widespread use of erythromycin for preterm prelabour rupture of membranes. Lancet. 2003, 361, 437.

28. Gygax SE, Schuyler JA, Trama JP, [et al.]. Detection of erythromycin and clindamycin resistance genes in Group B Streptococcal clinical isolates and cervicovaginal-rectal swabs. Microb Drug Resist. 2007, 13, 119-123.

29. Borahay MA, Harirah HM, Olson G, [et al.]. Disseminated intravascular coagulation, hemoperitoneum, and reversible ischemic neurological deficit complicating anaphylaxis to prophylactic antibiotics during cesarean delivery: A case report and review of literature. AJP Rep. 2011, $1,15-20$.

30. Sengupta A, Kohli JK. Antibiotic prophylaxis in cesarean section causing anaphylaxis and intrauterine fetal death. J Obstet Gynaecol Res. 2008, 34, 252-254.

31. Mulla ZD, Ebrahim MS, Gonzalez JL. Anaphylaxis in the obstetric patient: Analysis of a statewide hospital discharge database. Ann Allergy Asthma Immunol. 2010, 104, 55-59.

32. Jakobsson $\mathrm{HE}$, Jernberg $\mathrm{C}$, Andersson AF, [et al.]. Short-term antibiotic treatment has differing long-term impacts on the human throat and gut microbiome. PLoS One. 2010, 5, e9836.

33. Bedford Russell AR, Murch SH. Could peripartum antibiotics have delayed health consequences for the infant? BJOG. 2006, 113, 758-765.

34. Bizzarro MJ, Dembry LM, Baltimore RS, [et al.]. Changing patterns in neonatal Escherichia coli sepsis and ampicillin resistance in the era of intrapartum antibiotic prophylaxis. Pediatrics. 2008, 121, 689-696. 